\title{
Impact of patient and treatment characteristics on heart and lung dose in adjuvant radiotherapy for left-sided breast cancer
}

\author{
Tobias Finazzi $^{* \dagger}$ (B), Van-Trinh Nguyen ${ }^{\dagger}$, Frank Zimmermann and Alexandros Papachristofilou(D)
}

\begin{abstract}
Purpose: The heart and lungs are routinely exposed to incidental irradiation during adjuvant radiotherapy (RT) of breast cancer. We analyzed the impact of patient and treatment characteristics on heart and lung dose in left-sided breast RT.

Methods: We analyzed 332 female patients treated with left-sided breast RT between 2013 and 2018. Mean heart dose (MHD), left mean lung dose (MLD) and heart / lung $V_{20 G y}$ were collected from treatment plans. Patients were stratified by RT technique (3D-conformal RT, 3DCRT; intensity-modulated RT, IMRT; volumetric modulated arc therapy, VMAT) and target volumes, including lymph node RT (LN-RT). Patient characteristics (body mass index (BMI), heart and lung volume) were assessed using correlation analyses.
\end{abstract}

Results: LN-RT was performed in 111 patients with increased MHD (median 4.6 vs. 3.3 Gy; $p<.01$ ), left MLD (14.8 vs. $7.7 \mathrm{~Gy} ; p<.01)$ and left lung $V_{20 G y}(30.0 \%$ vs. $14.4 \% ; p<.01)$ compared to treatment without LN-RT. Internal mammary LN-RT further increased organ doses compared to RT involving only supraclavicular +/- axillary LN ( $p<.01$ for all values; MHD 6.9 vs. $4.2 \mathrm{~Gy}$ ). In 221 patients treated without LN-RT, IMRTNMAT was associated with higher left lung doses (MLD 9.1 vs. $7.4 \mathrm{~Gy}, p<.01 ; V_{20 G y} 18.8 \%$ vs. $14.0 \%, p<.01$ ) compared to 3DCRT. A negative correlation between total lung volume and both $\operatorname{MHD}(r=-0.38 ; p<.01)$ and heart $\mathrm{V}_{20 \mathrm{~Gy}}(r=-0.37 ; p<.01)$, as well as a weak positive correlation of BMl and MHD $(r=0.27 ; p<.01)$ were observed.

Conclusions: In adjuvant RT for left-sided breast cancer, LN-RT is associated with a marked increase in heart and lung doses, particularly with internal mammary LN-RT. Potential advantages of IMRTNMAT for breast or chest wall RT need to be weighed against a moderately increased lung dose.

Keywords: Breast cancer, Adjuvant radiotherapy, Organs at risk, Heart dose, Lung dose, Lymph nodes, Intensity-modulated radiotherapy

\section{Background}

Adjuvant radiotherapy (RT) is a standard procedure after surgery for breast cancer, reducing the risk of locoregional recurrence and breast cancer death after breast conserving surgery, as well as after mastectomy in highrisk patients $[1,2]$. Since most breast cancer patients are cured of their disease, potential long term hazards of RT

\footnotetext{
*Correspondence: tobias.finazzi@usb.ch

${ }^{\dagger}$ Tobias Finazzi and Van-Trinh Nguyen contributed equally to this work. Clinic of Radiotherapy and Radiation Oncology, University Hospital Basel, Petersgraben 4, 4031 Basel, Switzerland
}

need to be considered. In particular, incidental irradiation of the heart in left-sided breast RT has been linked with an increased risk of cardiac events [3-5]. In addition, radiation dose to the lung harbors the risk of radiation pneumonitis, lung fibrosis and secondary lung cancer $[4,6,7]$.

Although improved RT techniques can potentially better spare organs at risk (OAR), heart and lung dose remain important dosimetric surrogates for long term effects and hence influence clinical decision making in adjuvant RT for (left-sided) breast cancer. We analyzed

(C) The Author(s). 2019 Open Access This article is distributed under the terms of the Creative Commons Attribution 4.0 International License (http://creativecommons.org/licenses/by/4.0/), which permits unrestricted use, distribution, and 
the impact of patient and treatment characteristics on heart and lung dose in a contemporary cohort of patients treated with left-sided breast RT, aiming to better quantify potential relationships and allow for a more refined consideration of these factors in clinical practice.

\section{Materials and methods}

We retrospectively identified female patients treated with adjuvant RT for left-sided breast cancer (including ductal and lobular carcinoma in situ) in our institution between 1st April 2013 and 31st August 2018. Exclusion criteria were previous irradiation of the left breast, indications other than adjuvant (e.g. palliative) RT, partial breast irradiation, uncommon fractionation (single doses other than 1.8-2.67 Gy), and documented refusal of data collection for scientific purposes. This analysis was approved by the Ethics Committee Northwest and Central Switzerland (EKNZ).

Data on patient and treatment characteristics were collected from electronic medical records in MOSAIQ ${ }^{\circ}$ (Elekta, Stockholm, Sweden) and ISMed(c (ProtecData AG, Boswil, Switzerland). For each patient, size and weight were noted for calculation of the body mass index (BMI; $\left.\mathrm{kg} / \mathrm{m}^{2}\right)$. Individual heart and lung volumes $\left(\mathrm{cm}^{3}\right)$ were documented from planning computed tomography $(\mathrm{CT})$ data in stored RT plans. Treatment details were collected for each patient; this included RT technique, target volume and dose fractionation. Patients were generally treated in supine position with both arms above the head. Noted RT techniques were 3-dimensional conformal radiation therapy (3DCRT), intensity-modulated radiation therapy (IMRT), and volumetric modulated arc therapy (VMAT). When regional lymph nodes (LN) were irradiated, regions were noted separately as axillary, supraclavicular and internal mammary nodes (IMN), with axillary and supraclavicular LN typically representing levels $1-3$ and level 4, respectively, according to ESTRO consensus guideline, and the IMN extending caudally to the 4th -5 th rib [8].

For each patient, radiation dose to the heart and lung was collected from RT plans. Noted parameters, based on literature $[3,4,6,9]$ and feasibility of collection for all patients, were mean heart dose (MHD; Gy), left mean lung dose (MLD; Gy), as well as $\mathrm{V}_{20 G y}(\%)$ of the heart and left lung. In case of multiple RT plans, e.g. when $\mathrm{LN}$ regions were treated to a lower dose than the breast or chest wall, doses were collected from sum plans or summed up manually. In case of hypofractionated RT, due to the lower nominal prescription dose, MHD and left MLD were adjusted to a total dose of 50 Gy for the purpose of comparative analysis, and the $\mathrm{V}_{16 \text { Gy }}$ was documented as a physical dose equivalent (40\% of prescribed dose) to $\mathrm{V}_{20 \mathrm{~Gy}}$ in conventional fractionation. Boost plans to the tumor bed were ignored for this study.
Statistical analysis was performed using RStudio v1.1.456 (Boston, USA). Group comparisons were performed to analyze heart and lung doses for different RT techniques and target volumes, using two-tailed t-test and Wilcoxon rank sum test. The relationship between patient characteristics (BMI, heart and total lung volume) and radiation exposure of the heart and lung was assessed using Spearman's rank correlation coefficient. A $p$-value $<.05$ was considered to be statistically significant.

\section{Results}

\section{Treatment characteristics}

A total of 332 female patients treated with left-sided breast RT were eligible for analysis. Median age at time of RT was 59 years (range, [28-91]). Patients received a median dose of 50 Gy to the breast after breast-conserving surgery $(n=272)$, or to the chest wall after mastectomy $(n=60)$. Fractionation schemes were $50 \mathrm{~Gy}$ in 25 fractions $(n=119), 50.4 \mathrm{~Gy}$ in 28 fractions $(n=101)$, and $39.9 \mathrm{~Gy}$ in 15 fractions $(n=112)$. Irradiation of regional LN was performed in 33\% of cases $(n=111)$, most commonly $(80 \%)$ delivered with single doses of $1.8 \mathrm{~Gy}$ to a total dose of $45-50.4 \mathrm{~Gy}$.

Main treatment characteristics are summarized in Fig. 1. Overall, two-third (67\%) of patients were treated with 3DCRT $(n=223)$, whereas one third $(33 \%)$ received IMRT $(n=29)$ or VMAT $(n=80)$. As indicated in Fig. 1 , regional LN-RT more often involved usage of IMRT/VMAT compared to cases without LN-RT (IMRT/VMAT in 55.9\% vs. $21.3 \%$ of cases, respectively). When regional LN were treated, target volumes included the axillary LN (66.7\%), supraclavicular LN (88.3\%), and IMN (18.9\%), either exclusively or in combination.

Institutional time trends for delivery of left-sided breast radiotherapy are presented in Table 1 . The rate of patients receiving LN-RT increased over time, with $25.0 \%$ of patients receiving LN-RT in 2013-2014, compared to $37.5 \%$ in $2015-2018$. For the whole cohort, usage of IMRT/VMAT also increased during the observation period, with an overall IMRT/VMAT rate of 5.6\% in 2013-2014, compared to $46.0 \%$ in $2015-2018$.

\section{Impact of patient characteristics on heart and lung dose}

Patient characteristics, as well as heart and lung doses for the whole cohort, are summarized in Table 2. Median heart and total lung volumes were $495.6 \mathrm{~cm}^{3}$ (range, [271.6-1031.7]) and $2738.6 \mathrm{~cm}^{3}$ (range, [1591.3-5544.5]), respectively. Patient size and weight were available in 318 cases, resulting in a median BMI of $25.3 \mathrm{~kg} / \mathrm{m}^{2}$ (range, [16.3-54.7]). For the whole cohort of 332 patients, MHD and heart $\mathrm{V}_{20 \mathrm{~Gy}}$ were a median of $3.7 \mathrm{~Gy}$ and $3.1 \%$, respectively. Left lung mean dose and $\mathrm{V}_{20 \mathrm{~Gy}}$ were a median of $9.1 \mathrm{~Gy}$ and $18.1 \%$.

Overall, no strong correlation between patient anatomy and heart or lung dose was observed. Dose exposure of the 


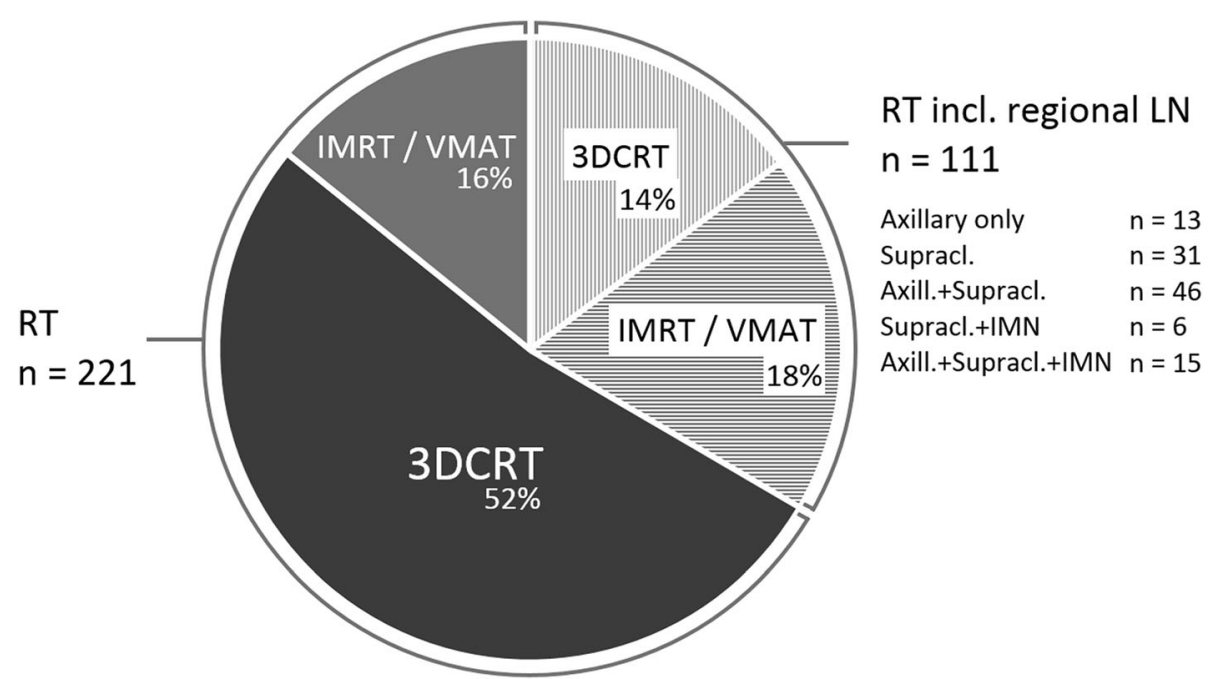

Fig. 1 Summary of treatment characteristics for all patients treated with adjuvant RT for left-sided breast cancer $(n=332)$. Abbreviations: RT, radiotherapy. 3DCRT, 3-dimensional conformal radiation therapy. IMRT, intensity modulated radiation therapy. VMAT, volumetric modulated arc therapy. LN, lymph nodes. Axill., axillary. Supracl., supraclavicular. IMN, internal mammary nodes

left lung (MLD, $\mathrm{V}_{20 G y}$ ) was not shown to be related to BMI, heart or lung volume. However, correlation analysis revealed a weak to moderate negative association between total lung volume and both $\operatorname{MHD}(r=-0.38 ; p<.01$; shown in Fig. 2) and heart $\mathrm{V}_{20 \mathrm{~Gy}}(r=-0.37 ; p<.01)$. This negative correlation was also seen in a separate analysis of patients with and without LN-RT, with similar effect size $(r=-0.36$ to $-0.41 ; p<.01)$. In addition, a weak positive correlation of BMI and MHD $(r=0.27 ; p<.01)$ was observed. This was verified separately for cases without LN-RT $(r=0.34 ; p<.01)$, although no such correlation was seen when LN-RT was performed $(r=0.15 ; p=0.12)$.

\section{Impact of treatment characteristics on heart and lung dose}

Box-and-whisker plots in Fig. 3 illustrate the impact of regional LN irradiation on OAR dose. Regional LN-RT significantly increased MHD (median 4.6 vs. $3.3 \mathrm{~Gy}$; $p<.01)$, left MLD (14.8 vs. 7.7 Gy; $p<.01)$ and $\mathrm{V}_{20 \mathrm{~Gy}}$ of the left lung $(30.0 \%$ vs. $14.4 \% ; p<.01)$, with a trend for increased heart $\mathrm{V}_{20 \mathrm{~Gy}}(4.0 \%$ vs. $3.0 \% ; p=.06)$, compared to RT of the breast or chest wall without LN-RT. In particular, RT involving the IMN further increased heart dose compared to RT involving only the supraclavicular +/- axillary LN (median MHD 6.9 vs. $4.2 \mathrm{~Gy}, p<.01$; heart $\mathrm{V}_{20 \mathrm{~Gy}} 8.0 \%$ vs. $3.0 \%, p<.01$ ). Radiation dose to the lung was also higher when IMN-RT was performed, compared to treatment of only the supraclavicular +/axillary LN (left MLD 16.9 vs. 14.5 Gy, $p<.01$; left lung $\mathrm{V}_{\text {20Gy }} 33.0 \%$ vs. $\left.30.0 \%, p<.01\right)$.

Overall, patients treated with IMRT or VMAT exhibited a higher MHD (median 4.5 vs. $3.3 \mathrm{~Gy} ; p<.01$ ), left MLD (13.6 vs. $8.1 \mathrm{~Gy} ; p<.01)$ and $\mathrm{V}_{20 \mathrm{~Gy}}$ of the left lung $(26.4 \%$ vs $15.7 \%, p<.01)$ compared to 3DCRT. A subgroup analysis of patients treated without LN-RT $(n=221)$ was performed. As illustrated in Fig. 4, a moderate increase with IMRT/VMAT compared to 3DCRT remained for left MLD (median 9.1 vs 7.4 Gy; $p<.01$ ) and $\mathrm{V}_{20 \mathrm{~Gy}}$ of the left lung $(18.8 \%$ vs $14.0 \% ; p<.01)$, whereas no difference in heart doses was observed.

Table 1 Institutional time trends for left-sided breast radiotherapy

\begin{tabular}{|c|c|c|c|c|}
\hline & & 2013-2014 & 2015-2016 & 2017-2018 \\
\hline Patients & & 108 & 131 & 93 \\
\hline Rate of LN-RT & & $25.0 \%$ & $35.1 \%$ & $40.9 \%$ \\
\hline \multirow[t]{3}{*}{ Rate of IMRT/NMAT use } & Total $(n=332)$ & $5.6 \%$ & $21.4 \%$ & $80.7 \%$ \\
\hline & Treatment with LN-RT $(n=111)$ & $22.2 \%$ & $43.5 \%$ & $94.7 \%$ \\
\hline & Treatment without LN-RT $(n=221)$ & $0.0 \%$ & $9.4 \%$ & $70.9 \%$ \\
\hline
\end{tabular}

Institutional time trends observed for delivery of left-sided breast radiotherapy. A marked increase in both regional LN-RT, and the use of IMRT/VMAT, was observed during the period of our study. Although mostly used for treatments involving regional LN-RT, IMRT/VMAT also became a common delivery technique for left-sided breast or chest wall RT, due to presumed benefits for dose homogeneity and conformity

Abbreviations: $L N-R T$ lymph node radiotherapy; IMRT intensity-modulated radiation therapy; VMA, volumetric modulated arc therapy 
Table 2 Patient characteristics and organ at risk doses

\begin{tabular}{|c|c|c|c|c|c|c|}
\hline & & Median & Min & 5th percentile & 95th percentile & Max \\
\hline Age at time of radiotherapy & & 59 & 28 & 39 & 80 & 91 \\
\hline \multicolumn{7}{|l|}{ Patient anatomy } \\
\hline & Heart volume & $495.6 \mathrm{~cm}^{3}$ & $271.6 \mathrm{~cm}^{3}$ & $353.6 \mathrm{~cm}^{3}$ & $696.9 \mathrm{~cm}^{3}$ & $1031.7 \mathrm{~cm}^{3}$ \\
\hline & Lung volume & $2738.6 \mathrm{~cm}^{3}$ & $1591.3 \mathrm{~cm}^{3}$ & $1991.5 \mathrm{~cm}^{3}$ & $4155.6 \mathrm{~cm}^{3}$ & $5544.5 \mathrm{~cm}^{3}$ \\
\hline & Body mass index & $25.3 \mathrm{~kg} / \mathrm{m}^{2}$ & $16.3 \mathrm{~kg} / \mathrm{m}^{2}$ & $19.1 \mathrm{~kg} / \mathrm{m}^{2}$ & $36.5 \mathrm{~kg} / \mathrm{m}^{2}$ & $54.7 \mathrm{~kg} / \mathrm{m}^{2}$ \\
\hline \multicolumn{7}{|l|}{ Organ at risk doses } \\
\hline & Heart mean dose (Gy) & $3.7 \mathrm{~Gy}$ & 0.4 Gy & $1.1 \mathrm{~Gy}$ & $7.4 \mathrm{~Gy}$ & 14.8 Gy \\
\hline & Heart V $20 G y(\%)$ & $3.1 \%$ & $0.0 \%$ & $0.0 \%$ & $10.3 \%$ & $39.0 \%$ \\
\hline & Left lung mean dose (Gy) & $9.1 \mathrm{~Gy}$ & $1.0 \mathrm{~Gy}$ & $4.5 \mathrm{~Gy}$ & 17.4 Gy & 19.6 Gy \\
\hline & Left lung $V_{20 G y}(\%)$ & $18.1 \%$ & $0.0 \%$ & $7.4 \%$ & $37.0 \%$ & $49.6 \%$ \\
\hline
\end{tabular}

Summary of patient characteristics and organ at risk doses for all patients treated with adjuvant radiotherapy for left-sided breast cancer $(n=332$ )

\section{Discussion}

We report on the impact of patient and treatment characteristics on heart and lung dose in a contemporary cohort of patients treated with left-sided breast RT. In summary, our results show that regional LN irradiation, and particularly RT of internal mammary LN, significantly increases heart and lung dose. Use of IMRT/VMAT moderately increases dose exposure of the left lung in RT of the breast or chest wall, whereas no strong correlation between patient anatomy and heart or lung dose was seen.
The observation of a higher heart and lung dose when treating the regional LN is not surprising. However, studies analyzing the magnitude of increase in contemporary clinical practice are limited. The clinical significance of accurately assessing this correlation stems from a more favorable view of regional LN-RT in many centers as well as clinical guidelines [10-12], following demonstration of improved outcomes in randomized trials [13-15].

The role of (left-sided) IMN-RT is particularly debated, mainly due to concerns about heart doses. In a randomized trial using 2-dimensional RT techniques,

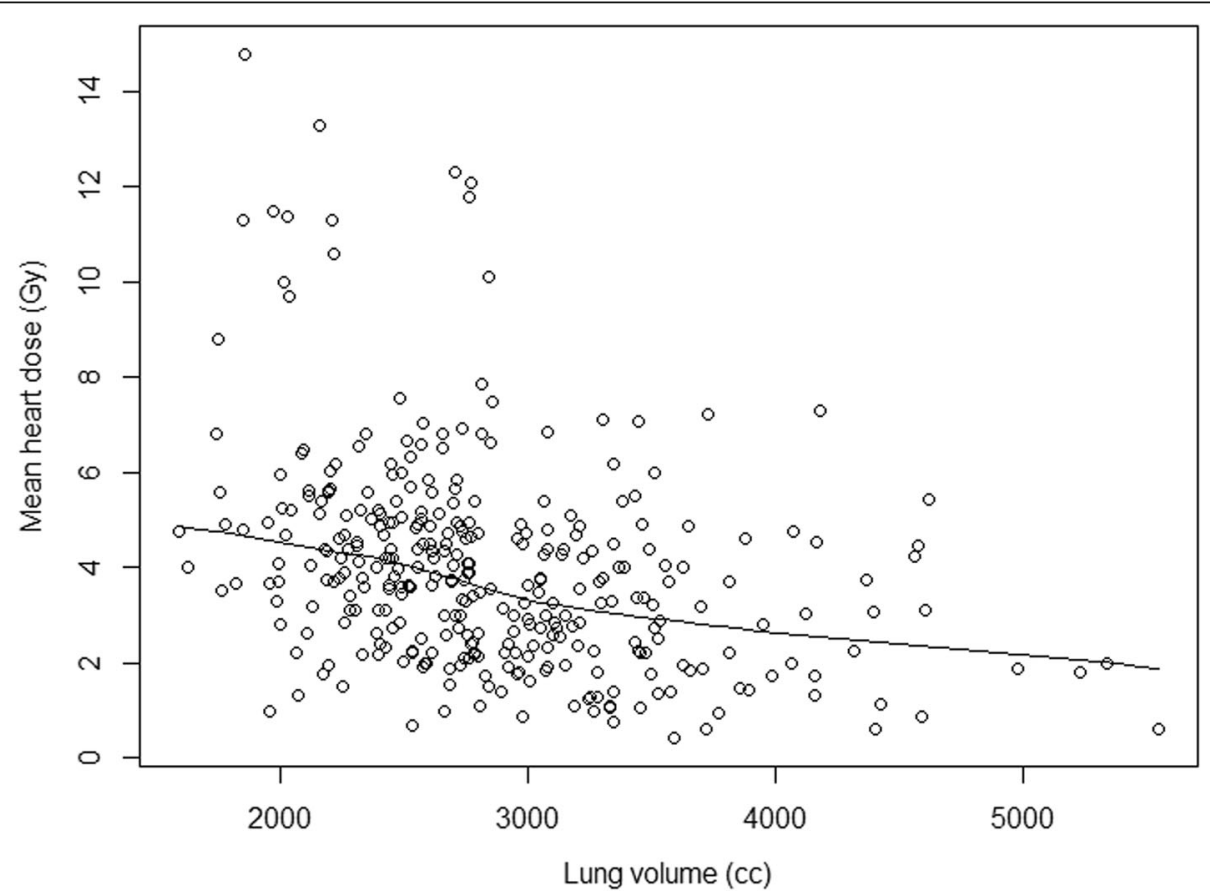

Fig. 2 Scatter plot of total lung volume (cc) and mean heart dose (Gy) for all patients ( $n=332)$. The fitted LOESS curve illustrates a weak to moderate negative correlation between lung volume and mean heart dose. Abbreviations: cc, cubic centimeter. LOESS, locally estimated scatterplot smoothing 


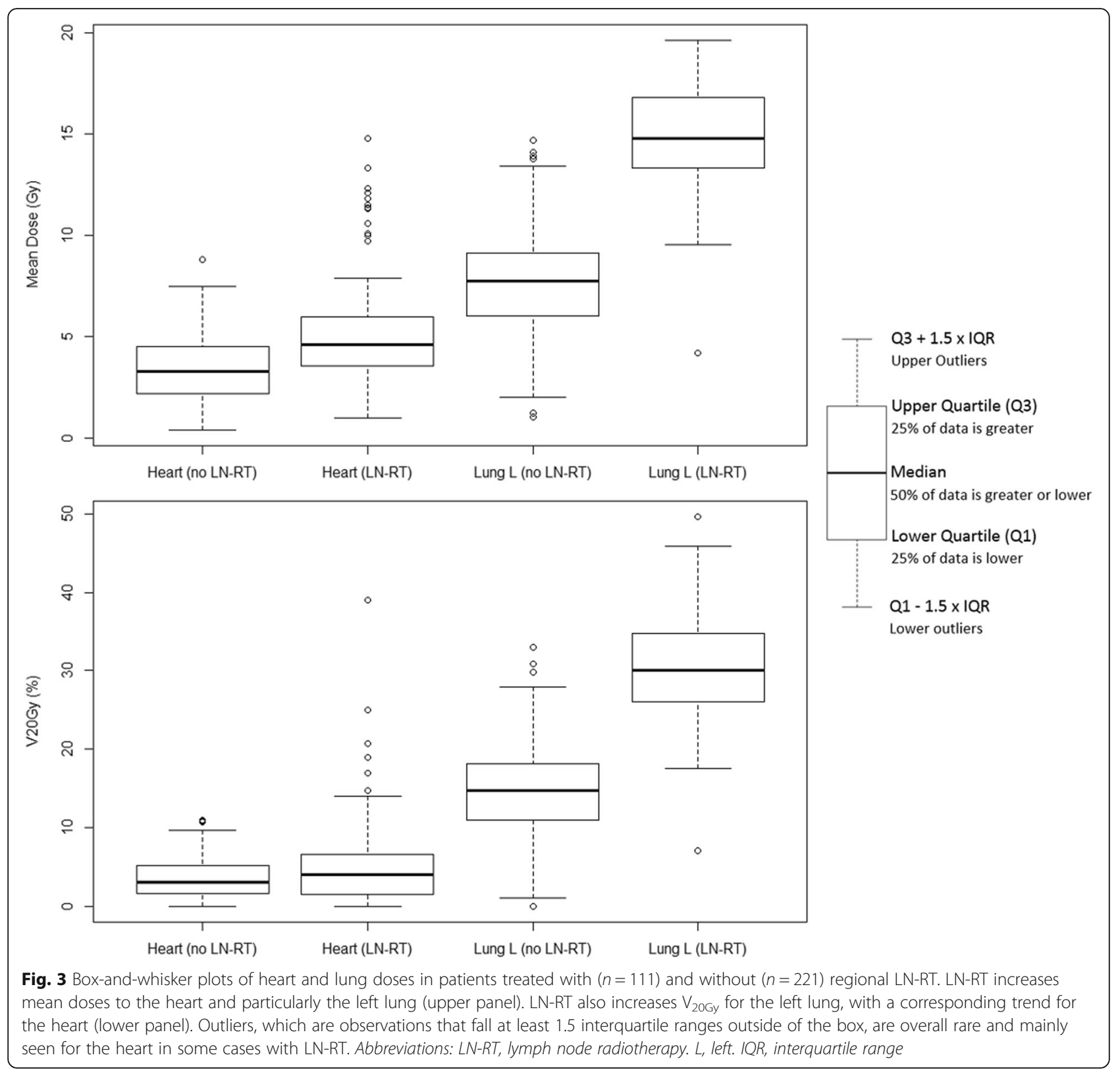

IMN-RT did not improve overall survival (OS), although a corresponding trend was observed [15, 16]. More recently, a prospective cohort study demonstrated increased OS for node-positive patients treated with IMNRT [17]. In our cohort, patients treated with IMN-RT exhibited the highest heart and lung doses, with an average MHD of $8.3 \mathrm{~Gy}$. This is almost identical to an average MHD of 8.4 Gy reported for left-sided IMN-RT in a systematic review [18]. Notably, our median MHD was lower than the mean, reflecting an observation of excessive doses in some cases with LN-RT (Fig. 3). In modern breast RT, the rate ratio (RR) of cardiac mortality has been estimated to increase by 0.04 per Gy MHD [4]. In our cohort, IMN-RT would therefore be associated with a RR of 1.33 of age-dependent cardiac mortality, compared to 1.18 when treating only the supraclavicular +/- axillary LN. These presumed risks of IMN-RT can be weighed against an absolute 8-year OS benefit of $3.7 \%$ in the aforementioned cohort study, which notably observed an equal number of cardiac deaths in patients receiving LN-RT with and without IMN-RT [17]. Contrary to some reports $[19,20]$, when excluding all types of LN-RT, we did not see an increase in MHD when IMRT or VMAT was used to treat the breast or chest wall. This may be a consequence of inverse treatment planning with priority given to heart sparing in left-sided breast radiotherapy, although lung doses should also be critically evaluted in treatment planning. 

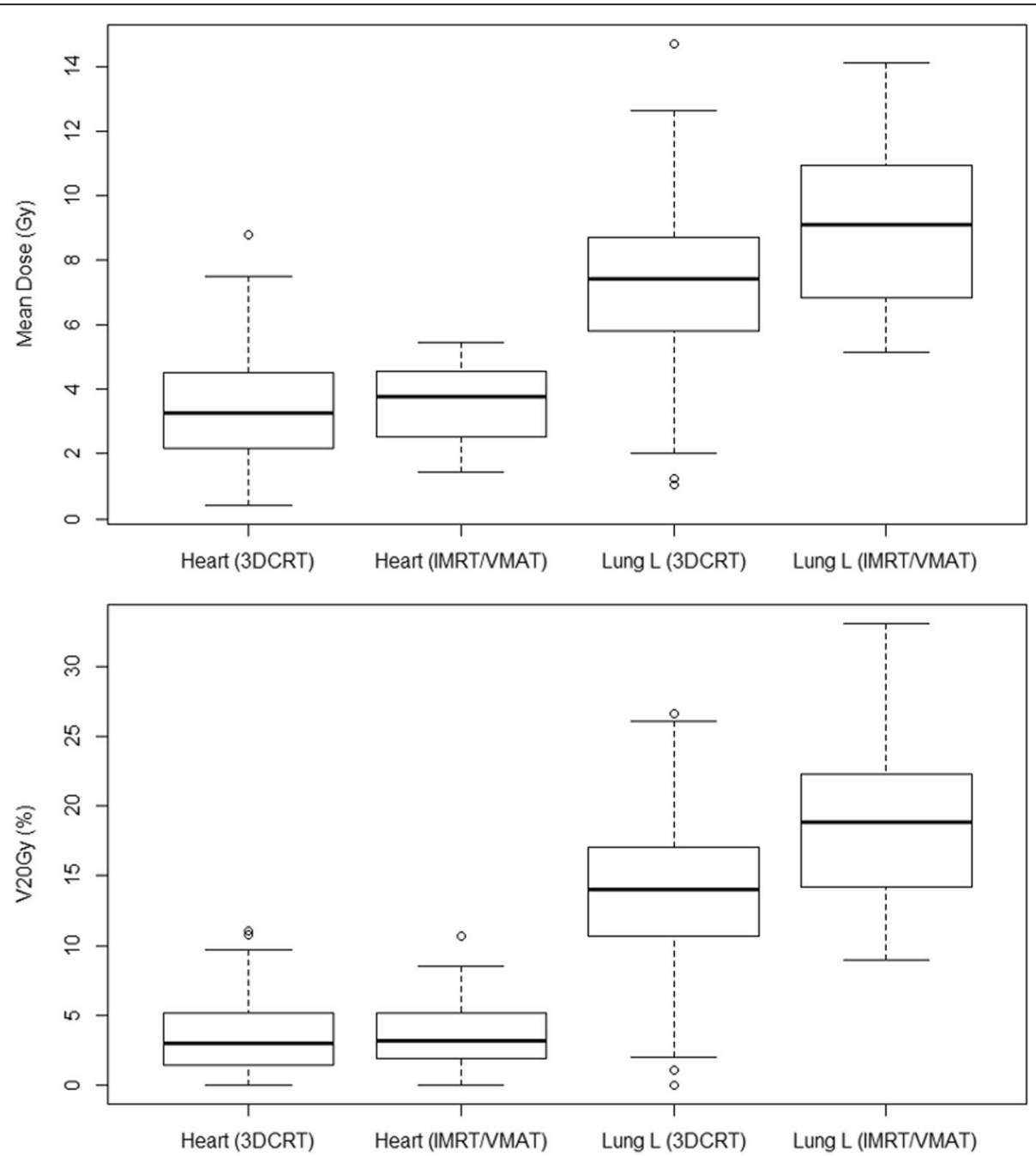

Fig. 4 Box-and-whisker plots of heart and lung doses for patients treated to the breast or chest wall without regional LN-RT, using either 3DCRT $(n=174)$ or IMRT/NMAT $(n=47)$. A significant increase in lung doses can be seen for patients treated with IMRT/NMAT, whereas the difference in heart doses is non-significant. Abbreviations: LN-RT, lymph node radiotherapy. 3DCRT, 3-dimensional conformal radiation therapy. IMRT, intensity modulated radiation therapy. VMAT, volumetric modulated arc therapy. L, left

We observed a remarkable difference in lung doses, with regional LN-RT doubling both MLD and $\mathrm{V}_{20 G y}$ of the left lung. Previous analyses have shown a significant impact of regional LN-RT, as well as IMRT use, on lung doses [7]. Considering the known risk of secondary lung cancer, as well as cardiac mortality, smoking cessation should be considered a necessity for these patients [4]. For patients receiving RT only to the breast or chest wall, the use of IMRT/VMAT was associated with a moderate increase in lung doses in our cohort. This may be explained by patient selection, since IMRT/VMAT was often used in challenging cases for which tangential fields were deemed unsuitable, such as large breasts or patients with a sunken chest (pectus excavatum). Still, when considering use of intensity-modulated RT techniques, a presumed benefit in dose homogeneity, conformity and target coverage needs to be weighed against potentially increased low-dose exposure, as well as workload and costs, on an individual basis [21, 22]. Similarly, factors affecting cosmesis and quality of life, such as lymphedema, as well as the more short-term risk of radiation pneumonitis, may outweigh the risk of late effects in RT planning, depending on patient age and comorbidities [21, 23]. Future studies will therefore need to systematically address long-term outcomes to assess the true benefits of different delivery techniques used for breast RT. Besides systematic recording of cardiac and pulmonary events, this includes evaluating the role of unintended lymph node irradiation with 3DCRT compared to IMRT/VMAT, as well as cosmesis and lymphedema-related issues. 
While we analyzed dosimetric parameters that are commonly used in clinical practice, it is important to note that their role as clinical predictors of toxicity is still a matter of ongoing debate. A case-control study of women who received breast RT between 1958 and 2001 found that the rate of major coronary events increased linearly with the MHD by $7.4 \%$ per gray, although heart doses were estimated retrospectively [3]. In contrast, more recent results indicate that the absolute cardiac risk after (left-sided) breast RT is likely much more modest using modern techniques $[4,5,19,24-26]$, and the rates of radiation pneumonitis and pulmonary fibrosis are still low when regional LN-RT is performed $[13,14]$.

To better estimate particularly the risk for cardiac late effects, standardized contouring of cardiac substructures has been proposed to improve consistency and precision of dose reporting [27, 28]. However, this has not found widespread clinical adoption, and dose to all cardiac segments should be minimized [29]. More effort has therefore been focused on reducing doses to OARs, and particularly the heart, using techniques such as RT in deep inspiration breath hold or prone positioning, which both can reduce the MHD [18, 20, 30-32]. Results of randomized trials may also lead to an increased use of partial breast irradiation in patients with early breast cancer [33-35].

\section{Conclusions}

In conclusion, we observed a marked increase in heart and lung doses when treating regional LN, and particularly the IMN, in a contemporary cohort of patients receiving left-sided breast RT. Use of IMRT/VMAT was associated with a moderate increase in lung doses when treating the breast or chest wall. These results add to the body of data on heart and lung exposure as a function of patient and treatment characteristics in contemporary breast RT, which may aid clinical decision making and help tailor personalized RT for these patients.

\section{Acknowledgements}

We would like to express our gratitude to our patients, and thank our team of radiation technologists, physicists, nurses, secretaries and physicians who were involved in their treatment

\section{Authors' contributions}

TF and VTN contributed equally to this study (co-first authors). TF, VTN, FZ and AP were all involved in the planning of this study. VTN was responsible for data collection. TF and VTN were responsible for the statistical analysis. TF wrote the first draft of the manuscript. All authors read and approved the final manuscript.

\section{Funding}

No funding was received for the conduction of this study.

\section{Availability of data and materials}

The datasets used and/or analysed during the current study are available from the corresponding author on reasonable request.

\section{Ethics approval and consent to participate}

This study was approved by the Ethics Committee Northwest and Central Switzerland (EKNZ). The ethics committee approved inclusion of patients into an anonymized database unless they had previously refused data collection for scientific purposes

\section{Consent for publication}

Not applicable.

\section{Competing interests}

TF, VTN, FZ and AP declare no competing interests.

Received: 14 May 2019 Accepted: 21 August 2019

Published online: 28 August 2019

\section{References}

1. Darby S, McGale P, Correa C, et al. Effect of radiotherapy after breastconserving surgery on 10-year recurrence and 15-year breast cancer death: meta-analysis of individual patient data for 10801 women in 17 randomised trials. Lancet. 2011;378:1707-16. https://doi.org/10.1016/50140-6 736(11)61629-2

2. P. M, C. T, S. D. Effect of radiotherapy after mastectomy and axillary dissection on recurrence and breast cancer mortality: meta-analysis of individual patient data from randomised trials. Eur J Cancer. 2014;50:S102.

3. Darby SC, Ewertz M, McGale P, et al. Risk of ischemic heart disease in women after radiotherapy for breast cancer. N Engl J Med. 2013;368:987-98. https://doi.org/10.1056/NEJMoa1209825.

4. Taylor C, Correa C, Duane FK, et al. Estimating the Risks of Breast Cancer Radiotherapy: Evidence From Modern Radiation Doses to the Lungs and Heart and From Previous Randomized Trials. J Clin Oncol. 2017:35(15):16419. https://doi.org/10.1200/JCO.2016.72.0722.

5. Boero IJ, Paravati AJ, Triplett DP, et al. Modern radiation therapy and cardiac outcomes in breast cancer. Int J Radiat Oncol Biol Phys. 2016;94:700-8. https://doi.org/10.1016/.jijrobp.2015.12.018.

6. Kwa SLS, Lebesque JV, Theuws JC, Marks LB. Radiation pneumonitis as a function of mean lung dose: an analysis of pooled data of 540 patients. Int J Radiat Oncol Biol Phys. 1998;42:1-9.

7. Aznar MC, Duane FK, Darby SC, et al. Exposure of the lungs in breast cancer radiotherapy: a systematic review of lung doses published 2010-2015. Radiother Oncol. 2018;1 26:148-54. https://doi.org/10.1016/.j.radonc.2017.11.022.

8. Offersen BV, Boersma LJ, Kirkove C, et al. ESTRO consensus guideline on target volume delineation for elective radiation therapy of early stage breast cancer. Radiother Oncol. 2015;114:3-10. https://doi.org/10.1016/j. radonc.2014.11.030

9. Marks L, Bentzen S, Deasy J, Kong F. Radiation dose volume effects in the lung. Int J Radiat Oncol Biol Phys. 2010;76:70-6. https://doi.org/10.1016/j. ijrobp.2009.06.091. Radiation.

10. NCCN. National Comprehensive Cancer Network Guidelines Version 3.2018: Breast Cancer; 2018. https://doi.org/10.1007/978-1-4614-8063-1.

11. Senkus E, Kyriakides S, Ohno S, et al. Primary breast cancer: ESMO clinical practice guidelines for diagnosis, treatment and follow-up. Ann Oncol. 2015; 26:v8-v30. https://doi.org/10.1093/annonc/mdw324.

12. S3-Leitlinien (2018) Interdisziplinäre S3-Leitlinie für die Früherkennung, Diagnostik, Therapie und Nachsorge des Mammakarzinoms (Version 4.1). https://doi.org/10.3238/arztebl.2018.0316

13. Poortmans PM, Collette S, Kirkove C, et al. Internal mammary and medial supraclavicular irradiation in breast Cancer. N Engl J Med. 2015;373:317-27. https://doi.org/10.1056/NEJMoa1415369.

14. Whelan TJ, Olivotto I a, Parulekar WR, et al. Regional nodal irradiation in early-stage breast Cancer. N Engl J Med. 2015;373:307-16. https://doi.org/1 0.1056/NEJMoa1415340

15. Budach W, Kammers K, Boelke E, Matuschek C. Adjuvant radiotherapy of regional lymph nodes in breast cancer - a meta-analysis of randomized trials. Radiat Oncol. 2013;8(267). https://doi.org/10.1186/1748-717X-8-267.

16. Hennequin C, Bossard N, Servagi-Vernat $\mathrm{S}$, et al. Ten-year survival results of a randomized trial of irradiation of internal mammary nodes after mastectomy. Int J Radiat Oncol Biol Phys. 2013;86:860-6. https://doi.org/10.1 016/j.jijobp.2013.03.021.

17. Thorsen LBJ, Offersen BV, Dano H, et al. DBCG-IMN: a population-based cohort study on the effect of internal mammary node irradiation in early 
node-positive breast Cancer. J Clin Oncol. 2016;34:314-20. https://doi.org/1 0.1200/JCO.2015.63.6456

18. Taylor CW, Zhe W, Macaulay E, et al. Exposure of the heart in breast cancer radiation therapy: a systematic review of heart doses published during 2003 to 2013. Int J Radiat Oncol Biol Phys. 2015;93:845-53. https://doi.org/10.1 016/.jijrobp.2015.07.2292.

19. Hong JC, Rahimy E, Gross CP, et al. Radiation dose and cardiac risk in breast cancer treatment: an analysis of modern radiation therapy including community settings. Pract Radiat Oncol. 2018;8:e79-86. https://doi.org/10.1 016/.j.pro.2017.07.005.

20. Pierce $L$, Feng $M$, Griffith KA, et al. Recent time trends and predictors of heart dose from breast radiation therapy in a large quality consortium of radiation oncology practices. Int J Radiat Oncol Biol Phys. 2012;99:1154-61. https://doi.org/10.1016/j.ijrobp.2017.07.022

21. Chan TY, Tan PW, Tang Jl. Intensity-modulated radiation therapy for earlystage breast cancer: is it ready for prime time? Breast Cancer(Dove Med Press). 2017;9:177-83. https://doi.org/10.2147/BCTT.S127583.

22. Ayata HB, Güden M, Ceylan C, et al. Comparison of dose distributions and organs at risk (OAR) doses in conventional tangential technique (CTT) and IMRT plans with different numbers of beam in left-sided breast cancer. Rep Pract Oncol Radiother. 2011;16:95-102. https://doi. org/10.1016/j.rpor.2011.02.001

23. Mukesh MB, Barnett GC, Wilkinson JS, et al. Randomized controlled trial of intensity-modulated radiotherapy for early breast cancer: 5-year results confirm superior overall cosmesis. J Clin Oncol. 2013;31:4488-95. https://doi. org/10.1200/JCO.2013.49.7842.

24. Patt DA, Goodwin JS, Kuo YF, et al. Cardiac morbidity of adjuvant radiotherapy for breast cancer. J Clin Oncol. 2005;23:7475-82. https://doi. org/10.1200/JCO.2005.13.755.

25. Giordano SH, Kuo YF, Freeman JL, et al. Risk of cardiac death after adjuvant radiotherapy for breast cancer. J Natl Cancer Inst. 2005;97:419-24. https:// doi.org/10.1093/jnci/dji067.

26. Weberpals J, Jansen L, Müller OJ, Brenner H. Long-term heart-specific mortality among 347476 breast cancer patients treated with radiotherapy or chemotherapy: a registry-based cohort study. Eur Heart J. 2018;39:38963903. https://doi.org/10.1093/eurheart//ehy167.

27. Feng $\mathrm{M}$, Moran JM, Koelling $\mathrm{T}$, et al. Development and validation of a heart atlas to study cardiac exposure to radiation following treatment for breast cancer. Int J Radiat Oncol Biol Phys. 2011;79:10-8. https://doi.org/10.1016/j. ijrobp.2009.10.058

28. Duma MN, Herr A-C, Borm K, et al. Tangential field radiotherapy for breast Cancer-the dose to the heart and heart subvolumes: what structures must be contoured in future clinical trials? Front Oncol. 2017;7:1-6. https://doi. org/10.3389/fonc.2017.00130.

29. Taylor C, McGale P, Brønnum D, et al. Cardiac structure injury after radiotherapy for breast cancer: cross-sectional study with individual patient data. J Clin Oncol. 2018;36:2288-96. https://doi.org/10.1200/ JCO.2017.77.6351.

30. Nguyen MH, Lavilla M, Kim JN, Fang LC. Cardiac sparing characteristics of internal mammary chain radiotherapy using deep inspiration breath hold for left-sided breast cancer. Radiat Oncol. 2018;13:1-8. https://doi.org/10.11 86/s13014-018-1052-8.

31. Nissen HD, Appelt AL. Improved heart, lung and target dose with deep inspiration breath hold in a large clinical series of breast cancer patients. Radiother Oncol. 2013;106:28-32. https://doi.org/10.1016/j. radonc.2012.10.016.

32. Remouchamps VM, Vicini FA, Sharpe MB, et al. Significant reductions in heart and lung doses using deep inspiration breath hold with active breathing control and intensity-modulated radiation therapy for patients treated with locoregional breast irradiation. Int J Radiat Oncol Biol Phys. 2003;55:392-406. https://doi.org/10.1016/50360-3016(02)04143-3.

33. Coles $\mathrm{CE}$, Griffin CL, Kirby AM, et al. Partial-breast radiotherapy after breast conservation surgery for patients with early breast cancer (UK IMPORT LOW trial): 5-year results from a multicentre, randomised, controlled, phase 3, non-inferiority trial. Lancet. 2017;390:1048-60. https://doi.org/10.1016/S0140-6736(17)31145-5.

34. Strnad V, Ott OJ, Hildebrandt G, et al. 5-year results of accelerated partial breast irradiation using sole interstitial multicatheter brachytherapy versus whole-breast irradiation with boost after breastconserving surgery for low-risk invasive and in-situ carcinoma of the female breast: a ran. Lancet. 2016;387:229-38. https://doi.org/10.1016/ S0140-6736(15)00471-7.

35. Vaidya JS, Wenz F, Bulsara M, et al. Risk-adapted targeted intraoperative radiotherapy versus whole-breast radiotherapy for breast cancer:5-year results for local control and overall survival from the TARGIT-A randomised trial. Lancet. 2014;383:603-13. https://doi.org/10.1016/S014 0-6736(13)61950-9.

\section{Publisher's Note}

Springer Nature remains neutral with regard to jurisdictional claims in published maps and institutional affiliations.
Ready to submit your research? Choose BMC and benefit from:

- fast, convenient online submission

- thorough peer review by experienced researchers in your field

- rapid publication on acceptance

- support for research data, including large and complex data types

- gold Open Access which fosters wider collaboration and increased citations

- maximum visibility for your research: over $100 \mathrm{M}$ website views per year

At BMC, research is always in progress.

Learn more biomedcentral.com/submissions 